\section{Research Article}

Check for updates

\section{OPEN ACCESS}

Received: Jul 6, 2019

Revised: Oct 27, 2019

Accepted: Nov 21, 2019

Fernandes RA, Strazzi-Sahyon HB, Suzuki TYU, Briso ALF, Santos PH

*Correspondence to Paulo Henrique dos Santos, DDS, MS, PhD Associate professor, Department of Dental Materials and Prosthodontics, School of Dentistry of Araçatuba, São Paulo State University, 1193 Vila Mendonça, Araçatuba, SP 16015-050, Brazil.

E-mail: paulo.santos@unesp.br

Copyright ( 2020 . The Korean Academy of Conservative Dentistry

This is an Open Access article distributed under the terms of the Creative Commons Attribution Non-Commercial License (https:// creativecommons.org/licenses/by-nc/4.0/) which permits unrestricted non-commercial use, distribution, and reproduction in any medium, provided the original work is properly cited.

Funding

This study was supported by the São Paulo Research Foundation (FAPESP) (Grant \#2011/06638-1).

Conflict of Interest

No potential conflict of interest relevant to this article was reported.

Author Contributions

Conceptualization: dos Santos PH; Data curation: Fernandes RA, Strazzi-Sahyon HB; Formal analysis: Fernandes RA, Strazzi-Sahyon

\title{
Effect of dental bleaching on the microhardness and surface roughness of sealed composite resins
}

\section{Renan Aparecido Fernandes $\left(\mathbb{D},{ }^{1}\right.$ Henrico Badaoui Strazzi-Sahyon $\mathbb{D}^{1},{ }^{1}$ Thaís Yumi Umeda Suzuki $\left(\mathbb{1},{ }^{2}\right.$ André Luiz Fraga Briso $(1),{ }^{3}$ Paulo Henrique dos Santos (ib) ${ }^{*}$}

'Department of Dental Materials and Prosthodontics, School of Dentistry of Araçatuba, São Paulo State University, Araçatuba, SP, Brazil

${ }^{2}$ Department of Restorative Dentistry, Federal University of Minas Gerais, Belo Horizonte, MG, Brazil ${ }^{3}$ Department of Restorative Dentistry, School of Dentistry of Araçatuba, São Paulo State University, Araçatuba, SP, Brazil

\section{ABSTRACT}

Objectives: The aim of this in vitro study was to evaluate the microhardness and surface roughness of composite resins before and after tooth bleaching procedures.

Materials and Methods: Sixty specimens were prepared of each composite resin (Filtek Supreme XT and Opallis), and BisCover LV surface sealant was applied to half of the specimens. Thirty enamel samples were obtained from the buccal and lingual surfaces of human molars for use as the control group. The surface roughness and microhardness were measured before and after bleaching procedures with $35 \%$ hydrogen peroxide or $16 \%$ carbamide $(n=10)$. Data were analyzed using 1-way analysis of variance and the Fisher test $(\alpha=0.05)$.

Results: Neither hydrogen peroxide nor carbamide peroxide treatment significantly altered the hardness of the composite resins, regardless of surface sealant application; however, both treatments significantly decreased the hardness of the tooth samples $(p<0.05)$. The bleaching did not cause any change in surface roughness, with the exception of the unsealed Opallis composite resin and dental enamel, both of which displayed an increase in surface roughness after bleaching with carbamide peroxide $(p<0.05)$.

Conclusions: The microhardness and surface roughness of enamel and Opallis composite resin were influenced by bleaching procedures.

Keywords: Composite resins; Hardness; Roughness; Tooth bleaching

\section{INTRODUCTION}

The process of dental bleaching has been a subject of discussion in dentistry because it is a conservative technique that is effective for whitening natural teeth [1-3], but conflicting results have been documented regarding its effects on restorative materials [4]. The bleaching agents in current use are peroxides in gel form, with concentrations ranging from $4 \%$ to $22 \%$ and from $25 \%$ to $40 \%$ for at-home and in-office bleaching techniques, respectively $[5,6]$.

Carbamide peroxide was introduced as an alternative to the traditional hydrogen peroxide, and its use has become widespread [7]. Carbamide peroxide is unstable and breaks down 
HB, Suzuki TYU, Briso ALF, dos Santos PH; Funding acquisition: Fernandes RA, dos Santos PH; Investigation: Fernandes RA, Strazzi-Sahyon HB, Suzuki TYU; Methodology: Suzuki TYU, Briso ALF, dos Santos PH; Project administration: dos Santos PH; Resources: Briso ALF, dos Santos PH; Supervision: dos Santos PH; Validation: Fernandes RA, StrazziSahyon HB, Suzuki TYU; Visualization: Briso ALF, dos Santos PH; Writing - original draft: Fernandes RA, Strazzi-Sahyon HB; Writing review \& editing: Suzuki TYU, Briso ALF, dos Santos $\mathrm{PH}$.

ORCID iDs

Renan Aparecido Fernandes https://orcid.org/0000-0001-8661-2427 Henrico Badaoui Strazzi-Sahyon (ID) https://orcid.org/0000-0001-7014-0437 Thaís Yumi Umeda Suzuki (D) https://orcid.org/0000-0003-4220-3781 André Luiz Fraga Briso (D) https://orcid.org/0000-0002-6126-1760 Paulo Henrique dos Santos (D) https://orcid.org/0000-0002-4100-5153 immediately upon contact with tissue and saliva, first dissociating into hydrogen peroxide and urea and subsequently into oxygen, water, and carbon dioxide $[4,8]$. The apparent mechanism of action of bleaching agents on tooth structures is the oxidation of dentin molecules, which causes color changes [9]. This oxidation reaction can interfere with the structural integrity of restorative materials [10].

Several studies have evaluated the effects of bleaching on teeth $[8,11,12]$ and dental materials $[4,10]$. However, the findings are conflicting. Some studies have shown that exposing hard dental tissue and restorative materials to bleaching agents can cause changes in their surfaces and decrease their microhardness [4,8,11-13]. Other research has demonstrated only minor changes or no changes in restorative materials $[14,15]$ and dental tissues $[4,16]$. Rough surfaces are known to be predisposed to extrinsic staining, bacterial adhesion, biofilm maturation, and periodontal disease [8]. The results of these studies imply that the effect of bleaching gels may be dependent on the composite material $[4,10]$.

The processes of finishing and polishing, while required to provide a restoration with a low surface roughness index and to maximize the aesthetics of the restorative material, may create small defects or microcracks on the restoration surface [17], with these defects ranging from 15 to $50 \mu \mathrm{m}$ [16]. Lee and Powers [18] proposed the development of a surface sealant able to fill the microcracks and reinforce the organic matrix to prevent color alteration of composite resin restorations. In addition, it improves the staining resistance of the composite, reducing the surface porosity and providing a more completely cured surface [19]. However, this sealant is expected to be effective for only some resin composites. In the current literature, few studies have evaluated the performance of composite resins treated with sealant material in dental bleaching procedures.

The aim of this study was to evaluate the Knoop microhardness and the surface roughness of healthy human enamel and composite resins, sealed or unsealed, before and after bleaching with carbamide peroxide or hydrogen peroxide. The tested null hypothesis was that no difference would be observed in the hardness and roughness of enamel and composite resin, sealed or unsealed, from before to after the bleaching procedures.

\section{MATERIALS AND METHODS}

\section{Preparation of resin samples}

In this study, a nanoparticle composite resin (Filtek Supreme XT, A2E shade, 3M ESPE, St. Paul, MN, USA) and a microhybrid composite resin (Opallis, EA2 shade, FGM, Joinville, SC, Brazil) were used. The composition of the materials used in this study is described in Table 1. Sixty specimens of each composite resin were prepared in a metal matrix $4 \mathrm{~mm}$ in diameter and $1.5 \mathrm{~mm}$ thick. The composite resin was covered using a polyester strip and a microscope slide, compressing the material to prevent bubble formation and to remove the excess material. Each specimen was light-cured according to the manufacturer's recommendations using a light-curing unit (Ultraled, Dabi Atlante, Ribeirão Preto, SP, Brazil) at an irradiance of $650 \mathrm{~mW} / \mathrm{cm}^{2}$. Immediately after curing, specimens were removed from the matrix and were stored in distilled water at $37^{\circ} \mathrm{C}$ for 24 hours.

After this period, the specimens were polished in a polisher machine (APL-4, Arotec Ind., Cotia, SP, Brazil) using silicon carbide discs of increasing granulation (\#360, \#600, and \#1200 special 
Table 1. Material, trademark, manufacturer, composition, and batch number of the substances used

\begin{tabular}{|c|c|c|c|c|}
\hline Material & Trademark & Manufacturer & Composition & Batch \# \\
\hline $\begin{array}{l}\text { Nanoparticle } \\
\text { composite resin }\end{array}$ & Filtek Supreme XT & 3M/ESPE (St. Paul, MN, USA) & $\begin{array}{l}\text { Ceramics treated with silane, bis-GMA, bis-EMA, silane-treated silica, } \\
\text { silica-zirconium oxide treated with silane, diurethane dimethacrylate, } \\
\text { polyethylene glycol dimethacrylate, TEGDMA, and 2,6-di-tert- } p \text {-cresol. }\end{array}$ & N275361BR \\
\hline $\begin{array}{l}\text { Microhybrid } \\
\text { composite resin }\end{array}$ & Opallis & FGM (Joinville, SC, Brazil) & $\begin{array}{l}\text { bis-GMA, bis-EMA, TEGDMA, urethane dimethacrylate and barium } \\
\text { aluminum silicate, silicon oxide nanoparticles, camphorquinone, } \\
\text { accelerators, stabilizers, and pigments. }\end{array}$ & 030911 \\
\hline Sealant surface & BisCover LV & Bisco (Schaumburg, IL, USA) & $\begin{array}{l}\text { Ethoxylated bisphenol A diacrylate, urethane acrylate ester, and } \\
\text { polyethylene glycol diacrylate. }\end{array}$ & 1100010361 \\
\hline $\begin{array}{l}\text { Hydrogen peroxide } \\
35 \%\end{array}$ & $\begin{array}{l}\text { Whiteness HP Maxx } \\
\qquad 35 \%\end{array}$ & FGM (Joinville, SC, Brazil) & $\begin{array}{l}\text { Hydrogen peroxide } 35 \% \text {, thickeners, dye mixtures, glycol, inorganic filler, } \\
\text { and deionized water. }\end{array}$ & 140711 \\
\hline $\begin{array}{l}\text { Carbamide peroxide } \\
16 \%\end{array}$ & $\begin{array}{l}\text { Whiteness Perfect } \\
\qquad 16 \%\end{array}$ & FGM (Joinville, SC, Brazil) & $\begin{array}{l}\text { Carbamide peroxide, neutralized carbopol, potassium nitrate, sodium } \\
\text { fluoride, humectant (glycol), and deionized water. }\end{array}$ & 020911 \\
\hline
\end{tabular}

bis-GMA, bisphenol A-glycidyl methacrylate; bis-EMA, ethoxylated bisphenol A glycol dimethacrylate; TEGDMA, triethylene glycol dimethacrylate.

silicon carbide grinding paper, Buehler, Lake Bluff, IL, USA). The specimens were cleaned in an ultrasonic unit (model 2210, Branson Ultrasonics, Danbury, CT, USA) with deionized water for 2 minutes between the use of each abrasive disc and at the end of the process.

Half of the specimens of each composite resin were etched with $32 \%$ phosphoric acid (3M ESPE) for 15 seconds, washed with distilled water, and dried with air jets. The surface sealant (BisCover LV, Bisco Inc., Schaumburg, IL, USA) was applied and was light-cured for 30 seconds according to the manufacturer's recommendations. The specimens were divided into 4 groups based on the type of composite resin used and the application or lack of application of the surface sealant.

\section{Preparation of enamel samples}

The study was approved by the Research and Ethics Committee (protocol 01529/2011) of our institution. Fifteen healthy human molars were selected, from which samples of enamel-4 $\mathrm{mm}$ in length, $4 \mathrm{~mm}$ in width, and $1.5 \mathrm{~mm}$ in thickness-were obtained from the buccal and lingual surfaces. Initially, the teeth were sectioned in the mesial-distal direction with a lowspeed diamond saw under water cooling using a cutting machine (Isomet 2000, Buehler). Then, the samples were finished and polished in an APL-4 polishing machine with \#360-, \#600-, and \#1200-grit silicon carbide paper. The specimens were cleaned in a model 2210 ultrasonic unit (Branson Ultrasonics) in the same fashion as the composite resin samples. Throughout the experimental period, the resin composite and enamel specimens were conditioned in a light-proof container and stored in distilled water at $37^{\circ} \mathrm{C}$.

\section{Determination of Knoop microhardness}

Knoop microhardness measurements were made using a microindentation tester (Microhardness Tester HMV-2.0, Shimadzu, Kyoto, Japan) with a 25-g load applied for 10 seconds. The specimens were fixed individually and positioned perpendicular to the tester tip, and Knoop microhardness values were measured using CAMS-WIN software (New Age Industries, Southampton, PA, USA). Five indentations in each specimen (enamel and composite resin) were made, and the average microhardness value was calculated before and after bleaching procedures.

\section{Evaluation of surface roughness}

The surface roughness was measured using a profilometer (model SJ-401, Mitutoyo, Kawasaki, Japan), which had been calibrated prior to the readings. Each of a total of 3 measurements was obtained after turning the specimen $120^{\circ}$, using a cutoff of $0.25 \mathrm{~mm}$, and the arithmetic mean was calculated of the measurements taken before and after the bleaching procedures. 


\section{Bleaching procedures}

After the initial readings, 5 enamel samples and 10 specimens of each sealed and unsealed composite resin were subjected to bleaching with $35 \%$ hydrogen peroxide or $16 \%$ carbamide peroxide, with the control group exposed to distilled water.

The bleaching procedure with 35\% hydrogen peroxide (Whiteness HP Maxx, FGM) involved the application of $0.1 \mathrm{~mL}$ of the product for 15 minutes, followed by 2 additional applications in the same session. Between each application, the specimens were washed with distilled water and dried with sterile gauze, yielding a total of 45 minutes per session. One session involving 3 applications of the product was conducted per week, at 0 (baseline), 7, and 14 days, according to the manufacturer's specifications. After each bleaching procedure, the samples were washed and were stored in distilled water at $37^{\circ} \mathrm{C}$ until the next session.

Bleaching with 16\% carbamide peroxide (Whiteness Perfect, FGM) was performed by applying $0.1 \mathrm{~mL}$ of the product to the samples once a day for 4 hours; this was repeated for 14 days. After bleaching sessions, the samples were washed and stored in distilled water at $37^{\circ} \mathrm{C}$ until the next session. The samples of the control group were kept in distilled water during the 14 days of the experimental period. The surface roughness and microhardness values were evaluated again after the bleaching procedures.

\section{Statistical analysis}

The data regarding microhardness and surface roughness were tested for normality using the Shapiro-Wilk test and analyzed using 1-way analysis of variance and the Fisher least significant difference test $(\alpha=0.05)$.

\section{RESULTS}

As shown in Table 2, bleaching with carbamide or hydrogen peroxide did not significantly alter the microhardness values of the composite resins, with or without sealant application. The Opallis composite resin, regardless of sealant application, showed an increase in hardness after storage in distilled water (the control group), which constituted a significant difference from the other groups $(p<0.05)$.

In the analysis of surface roughness, in general, the bleaching processes did not cause statistically significant alterations (Table 3). The exception was for the unsealed Opallis composite resin, for which bleaching with carbamide peroxide promoted an increase in surface roughness $(p=0.027)$. The enamel samples stored in distilled water showed higher surface roughness values than the samples bleached with hydrogen peroxide $(p<0.05)$.

Table 2. Mean values of Knoop microhardness before and after bleaching with carbamide peroxide, hydrogen peroxide, and distilled water (control) for all materials used

\begin{tabular}{lcccr}
\hline Materials & Before bleaching & $\begin{array}{c}\text { After bleaching with } \\
16 \% \text { carbamide peroxide }\end{array}$ & $\begin{array}{c}\text { After bleaching with } \\
35 \% \text { hydrogen peroxide }\end{array}$ & Control \\
\hline Opallis & $83.5 \pm 4.5^{\mathrm{b}}$ & $80.4 \pm 6.6^{\mathrm{b}}$ & $80.5 \pm 4.9^{\mathrm{b}}$ & $91.2 \pm 4.3^{\mathrm{a}}$ \\
Opallis + BisCover & $24.5 \pm 2.5^{\mathrm{b}}$ & $25.4 \pm 2.6^{\mathrm{b}}$ & $25.6 \pm 2.3^{\mathrm{b}}$ & $28.1 \pm 0.8^{\mathrm{a}}$ \\
Supreme XT & $92.9 \pm 4.1^{\mathrm{a}}$ & $93.1 \pm 2.2^{\mathrm{a}}$ & $93.0 \pm 1.5^{\mathrm{a}}$ & $95.0 \pm 7.6^{\mathrm{a}}$ \\
Supreme XT + BisCover & $28.1 \pm 2.9^{\mathrm{a}}$ & $28.4 \pm 1.7^{\mathrm{a}}$ & $29.5 \pm 3.8^{\mathrm{a}}$ & $28.4 \pm 2.3^{\mathrm{a}}$ \\
Enamel & $423.9 \pm 30.5^{\mathrm{a}}$ & $200.0 \pm 23.8^{\mathrm{b}}$ & $163.6 \pm 54.9^{\mathrm{b}}$ & $398.6 \pm 0.0^{\mathrm{a}}$ \\
\hline Data shown are mean \pm standard deviation. & & \\
a,b Lowercase superscripts indicate statistically significant differences $(p<0.05)$ between values in the same row.
\end{tabular}


Table 3. Mean values of roughness before and after bleaching with carbamide peroxide, hydrogen peroxide, and distilled water (control) for all materials used

\begin{tabular}{lcccc}
\hline Materials & Before bleaching & $\begin{array}{c}\text { After bleaching with } \\
16 \% \text { carbamide peroxide }\end{array}$ & $\begin{array}{c}\text { After bleaching with } \\
35 \% \text { hydrogen peroxide }\end{array}$ & Control \\
\hline Opallis & $0.037 \pm 0.007^{\mathrm{b}}$ & $0.048 \pm 0.029^{\mathrm{a}}$ & $0.032 \pm 0.003^{\mathrm{b}}$ & $0.035 \pm 0.004^{\mathrm{b}}$ \\
Opallis + BisCover & $0.030 \pm 0.007^{\mathrm{a}}$ & $0.032 \pm 0.005^{\mathrm{a}}$ & $0.030 \pm 0.004^{\mathrm{a}}$ & $0.026 \pm 0.004^{\mathrm{a}}$ \\
Supreme XT & $0.028 \pm 0.005^{\mathrm{a}}$ & $0.029 \pm 0.004^{\mathrm{a}}$ & $0.029 \pm 0.002^{\mathrm{a}}$ & $0.027 \pm 0.005^{\mathrm{a}}$ \\
Supreme XT + BisCover & $0.027 \pm 0.006^{\mathrm{a}}$ & $0.029 \pm 0.005^{\mathrm{a}}$ & $0.029 \pm 0.003^{\mathrm{a}}$ & $0.026 \pm 0.005^{\mathrm{a}}$ \\
Enamel & $0.059 \pm 0.017^{\mathrm{a}, \mathrm{b}}$ & $0.067 \pm 0.013^{\mathrm{a}}$ & $0.048 \pm 0.008^{\mathrm{b}}$ & $0.071 \pm 0.008^{\mathrm{a}}$ \\
\hline
\end{tabular}

Data shown are mean \pm standard deviation.

a,b Lowercase superscripts indicate statistically significant differences $(p<0.05)$ between values in the same row.

\section{DISCUSSION}

In the present study, it was observed that bleaching with carbamide or hydrogen peroxide did not significantly alter the microhardness of composite resins, regardless of sealant application. These findings are in alignment with previous studies that showed that microhardness values were maintained for composite resins bleached with carbamide peroxide or hydrogen peroxide [20]. However, other studies have reported a decrease in the microhardness of composite resins submitted to dental bleaching [21-23]. These divergences can likely be explained by differences in the bleaching protocol (including time of application and treatment), bleaching agents, and restorative materials used [24].

Regardless of the type of bleaching protocol (carbamide peroxide or hydrogen peroxide), the materials sealed with the BisCover LV surface sealant exhibited lower microhardness values than the unsealed materials (Table 2). The sealant is mainly composed of resin monomers and therefore contains a lower quantity of inorganic matrix in relation to composite resins (Table 1) [4], which may have contributed to the relatively lower microhardness values of the sealed materials. The maintenance of the microhardness values and surface roughness of the sealed materials after the bleaching procedures could indicate that the sealant remained on the composites, showing that the material could withstand bleaching procedures, as well as the decrease in $\mathrm{pH}$ caused by such procedures.

The results also demonstrated that bleaching with hydrogen peroxide or carbamide peroxide promoted a statistically significant decrease in the microhardness of the enamel samples studied $(p<0.05)$, for which reason the null hypothesis of the study was rejected. Some studies have reported a loss of calcium [9,11,25-27], alterations in surface morphology $[28,29]$, changed in chemical composition [30], and a decrease in enamel microhardness $[25,28]$ in teeth subjected to bleaching procedures, the last of which was observed in the present study. These findings could be explained by daily exposure to bleaching substances with $\mathrm{pH}$ values ranging between 5.2 and 5.8 , which could initiate a descaling process involving the loss of minerals such as calcium [31]. During the bleaching process, enamel demineralization is associated with the oxidation mechanism, the $\mathrm{pH}$ of the peroxides, and certain components of the bleaching agents. The formation of free radicals occurs during the oxidation of peroxide. These free radicals act nonspecifically and can degrade both the organic and inorganic matrix of the substrate, causing enamel loss [32].

Moreover, the absence of saliva causes the recovery of minerals not to occur properly, resulting in a structural decrease in microhardness [33]. However, these results should be interpreted cautiously, as the remineralizing role of saliva is expected to reduce the adverse 
effects of low pH when the teeth are in use in the oral cavity [26]. Thus, the more that studies can simulate intraoral conditions, the lower the risk of the hardness being reduced [34].

The Opallis composite resin exhibited an increase in surface roughness after the carbamide peroxide bleaching protocol (Table 3). This result resembles those of studies that demonstrated that the use of hydrogen peroxide $(30 \%-35 \%)$ or $10 \%$ carbamide peroxide for more than 21 days resulted in changes in the surface roughness of this restorative material [14]. Gladys et al. [35] found that for composite resins, the surface roughness is determined mainly by the presence of filler particles found above the resin matrix. The carbamide peroxide protocol, because of its higher frequency of exposure and longer exposure time, may have altered the resin matrix of the composite resin, whereas the inorganic particles are inert, even in an extremely acidic environment. Thus, it is suggested that the matrix erosion occurs with the consequent displacement of inorganic particles, which is supported by the finding that some composite resins are more susceptible than others to different bleaching formulations and that certain applications may be especially likely to cause surface roughness changes [4]. Furthermore, the lower quantity of filler and the presence of more organic matrix in the microparticulate resin makes the material particularly susceptible to the erosive action of bleaching agents (Table 1); this causes the exposure of particles and porosities previously included inside the restoration, along with the possible formation of cracks, which may explain the increased roughness of this resin. However, the findings of most studies in the literature align with the results of this study, in which we observed little or no change in the surface roughness of these materials. Longitudinal clinical studies and clinical follow-up evaluations should be conducted to evaluate the long-term performance of these restorative materials after aesthetic procedures involving bleaching agents.

\section{CONCLUSIONS}

Based on the results of the present study, it can be concluded that enamel microhardness was influenced by both dental bleaching procedures used. In addition, bleaching with carbamide peroxide increased the surface roughness of the unsealed Opallis composite resin.

\section{REFERENCES}

1. Benetti F, Briso ALF, Ferreira LL, Carminatti M, Álamo L, Ervolino E, Dezan-Júnior E, Cintra LTA. In vivo study of the action of a topical anti-inflammatory drug in rat teeth submitted to dental bleaching. Braz Dent J 2018;29:555-561. PUBMED | CROSSREF

2. Bezerra-Júnior DM, Silva LM, Martins Lde M, Cohen-Carneiro F, Pontes DG. Esthetic rehabilitation with tooth bleaching, enamel microabrasion, and direct adhesive restorations. Gen Dent 2016;64:60-64. PUBMED

3. Gallinari MO, Fagundes TC, da Silva LM, de Almeida Souza MB, Barboza A, Briso A. A new approach for dental bleaching using violet light with or without the use of whitening gel: study of bleaching effectiveness. Oper Dent 2019;44:521-529. PUBMED | CROSSREF

4. Markovic L, Jordan RA, Glasser MC, Arnold WH, Nebel J, Tillmann W, Ostermann T, Zimmer S. Effects of bleaching agents on surface roughness of filling materials. Dent Mater J 2014;33:59-63. PUBMED | CROSSREF

5. Briso ALF, Rahal V, Azevedo FA, Gallinari MO, Gonçalves RS, Frascino SMB, Santos PHD, Cintra LTA. Neurosensory analysis of tooth sensitivity during at-home dental bleaching: a randomized clinical trial. J Appl Oral Sci 2018;26:e20170284. PUBMED | CROSSREF 
6. Esmaeili B, Abolghasemzadeh F, Gholampor A, Daryakenari G. The effect of home bleaching carbamide peroxide concentration on the microhardness of dental composite resins. Gen Dent 2018;66:40-44. PUBMED

7. Gallinari MO, Cintra LTÂ, Benetti F, Rahal V, Ervolino E, Briso ALF. Pulp response of rats submitted to bleaching and the use of different anti-inflammatory drugs. PLoS One 2019;14:e0210338. PUBMED | CROSSREF

8. Moraes RR, Marimon JL, Schneider LF, Correr Sobrinho L, Camacho GB, Bueno M. Carbamide peroxide bleaching agents: effects on surface roughness of enamel, composite and porcelain. Clin Oral Investig 2006;10:23-28. PUBMED | CROSSREF

9. Louzada LM, Briso ALF, Benetti F, Vieira LB, de Castilho Jacinto R, Dezan-Júnior E, Cintra LTA. Anti-inflammatory potential of a carvedilol gel in the pulpal tissue of rats after dental bleaching: a histopathological evaluation. J Investig Clin Dent 2019;10:e12401. PUBMED | CROSSREF

10. de Alexandre RS, Sundfeld RH, Briso AL, Bedran-Russo AK, Valentino TA, Sundefeld ML. Effect of $10 \%$ carbamide peroxide dental bleaching on microhardness of filled and unfilled sealant materials. J Esthet Restor Dent 2006;18:273-278. PUBMED | CROSSREF

11. Pinto CF, Oliveira Rd, Cavalli V, Giannini M. Peroxide bleaching agent effects on enamel surface microhardness, roughness and morphology. Braz Oral Res 2004;18:306-311. PUBMED | CROSSREF

12. Worschech CC, Rodrigues JA, Martins LR, Ambrosano GM. Brushing effect of abrasive dentifrices during at-home bleaching with 10\% carbamide peroxide on enamel surface roughness. J Contemp Dent Pract 2006;7:25-34. PUBMED | CROSSREF

13. Furlan IS, Bridi EC, Amaral FLBD, França FMG, Turssi CP, Basting RT. Effect of high- or lowconcentration bleaching agents containing calcium and/or fluoride on enamel microhardness. Gen Dent 2017;65:66-70. PUBMED

14. Turker SB, Biskin T. Effect of three bleaching agents on the surface properties of three different esthetic restorative materials. J Prosthet Dent 2003;89:466-473. PUBMED | CROSSREF

15. Wattanapayungkul P, Yap AU, Chooi KW, Lee MF, Selamat RS, Zhou RD. The effect of home bleaching agents on the surface roughness of tooth-colored restoratives with time. Oper Dent 2004;29:398-403. PUBMED

16. Kawai K, Leinfelder KF. Effect of surface-penetrating sealant on composite wear. Dent Mater 1993;9:108-113. PUBMED | CROSSREF

17. Rodrigues CS, Mozzaquatro LR, Dala Nora B, Jacques LB, Mallmann A. Effect of bleaching on color stability and roughness of composite resins aged in staining beverage. Gen Dent 2017;65:e5-e10. PUBMED

18. Lee YK, Powers JM. Combined effects of staining substances on resin composites before and after surface sealant application. J Mater Sci Mater Med 2007;18:685-691. PUBMED | CROSSREF

19. Mujdeci A, Gokay O. Effect of bleaching agents on the microhardness of tooth-colored restorative materials. J Prosthet Dent 2006;95:286-289. PUBMED | CROSSREF

20. Polydorou O, Mönting JS, Hellwig E, Auschill TM. Effect of in-office tooth bleaching on the microhardness of six dental esthetic restorative materials. Dent Mater 2007;23:153-158. PUBMED | CROSSREF

21. Gurgan S, Yalcin F. The effect of 2 different bleaching regimens on the surface roughness and hardness of tooth-colored restorative materials. Quintessence Int 2007;38:e83-e87. PUBMED

22. Lima DA, De Alexandre RS, Martins AC, Aguiar FH, Ambrosano GM, Lovadino JR. Effect of curing lights and bleaching agents on physical properties of a hybrid composite resin. J Esthet Restor Dent 2008;20:266-273. PUBMED | CROSSREF

23. Yu H, Li Q, Cheng H, Wang Y. The effects of temperature and bleaching gels on the properties of toothcolored restorative materials. J Prosthet Dent 2011;105:100-107.

PUBMED | CROSSREF 
24. Yu H, Li Q, Hussain M, Wang Y. Effects of bleaching gels on the surface microhardness of tooth-colored restorative materials in situ. J Dent 2008;36:261-267. PUBMED | CROSSREF

25. Al-Salehi SK, Wood DJ, Hatton PV. The effect of 24 h non-stop hydrogen peroxide concentration on bovine enamel and dentine mineral content and microhardness. J Dent 2007;35:845-850.

PUBMED | CROSSREF

26. Justino LM, Tames DR, Demarco FF. In situ and in vitro effects of bleaching with carbamide peroxide on human enamel. Oper Dent 2004;29:219-225.

PUBMED

27. Tezel H, Ertaş OS, Ozata F, Dalgar H, Korkut ZO. Effect of bleaching agents on calcium loss from the enamel surface. Quintessence Int 2007;38:339-347. PUBMED

28. Bistey T, Nagy IP, Simó A, Hegedus C. In vitro FT-IR study of the effects of hydrogen peroxide on superficial tooth enamel. J Dent 2007;35:325-330. PUBMED | CROSSREF

29. Jiang T, Ma X, Wang Y, Tong H, Shen X, Hu Y, Hu J. Investigation of the effects of $30 \%$ hydrogen peroxide on human tooth enamel by Raman scattering and laser-induced fluorescence. J Biomed Opt 2008;13:014019. PUBMED | CROSSREF

30. Jiang T, Ma X, Wang Z, Tong H, Hu J, Wang Y. Beneficial effects of hydroxyapatite on enamel subjected to 30\% hydrogen peroxide. J Dent 2008;36:907-914. PUBMED | CROSSREF

31. Basting RT, Antunes EV, Turssi CP, do Amaral FL, Franca FM, Florio FM. In vitro evaluation of calcium and phosphorus concentrations in enamel submitted to an in-office bleaching gel treatment containing calcium. Gen Dent 2015;63:52-56. PUBMED

32. Alexandrino L, Gomes Y, Alves E, Costi H, Rogez H, Silva C. Effects of a bleaching agent with calcium on bovine enamel. Eur J Dent 2014;8:320-325. PUBMED | CROSSREF

33. Henn-Donassollo S, Fabris C, Gagiolla M, Kerber Í, Caetano V, Carboni V, Salas MM, Donassollo TA, Demarco FF. In situ and in vitro effects of two bleaching treatments on human enamel hardness. Braz Dent J 2016;27:56-59. PUBMED | CROSSREF

34. Araujo NC, da Costa Soares MU, Nery MM, Sales WS, Gerbi ME. Effect of pH values of two bleaching gels on enamel microhardness. Gen Dent 2013;61:55-58. PUBMED

35. Gladys S, Van Meerbeek B, Braem M, Lambrechts P, Vanherle G. Comparative physico-mechanical characterization of new hybrid restorative materials with conventional glass-ionomer and resin composite restorative materials. J Dent Res 1997;76:883-894.

PUBMED | CROSSREF 